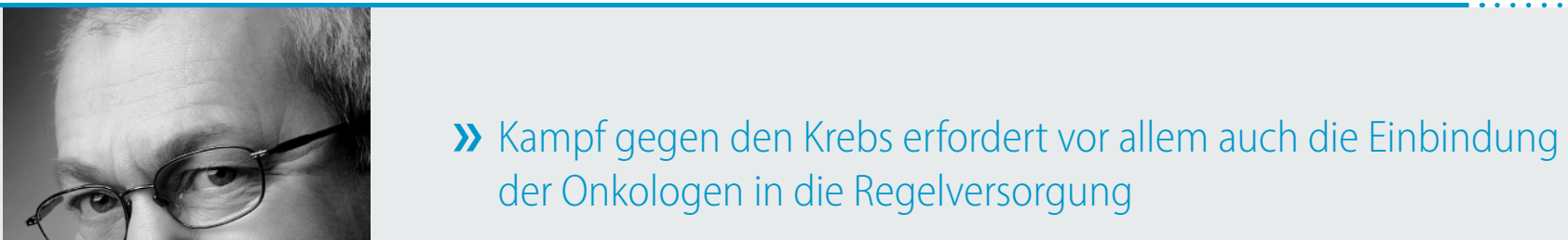

Prof. Dr. Stephan Schmitz

MVZ für Hämatologie und Onkologie Köln

Sachsenring 69

50677 Köln

\title{
Nationale Dekade gegen Krebs
}

Bundesforschungsministerin Anja Karliczek (CDU) hat am 1. Februar im Bundestag eine neue Initiative gegen den Krebs vorgestellt. Vollmundige Ziele wurden dabei verkündet: „Wir wollen Krebs besser verstehen, wir wollen Krebs verhindern, wir wollen Krebs heilen. “Es sollen neben den Standorten Heidelberg und Dresden weitere exzellente Forschungseinrichtungen unterstützt werden. In der „nationalen Dekade gegen Krebs“ sollen über 10 Jahre 62 Mio. EUR für mindestens 4 neue Tumorzentren eingeplant werden.

Die Unterstützung von 4 zusätzlichen Zentren ist sicher begrüßenswert, aber für einen erfolgreichen Kampf gegen den Krebs vollkommen unzureichend. Kampf gegen den Krebs erfordert sehr viel mehr. Neben der Grundlagenforschung und der translationalen Forschung, neben der pharmazeutischen Forschung und von der Pharmaindustrie unabhängigen klinischen
Studien ist schließlich der Transfer der Forschungsergebnisse zu den Patienten das wichtigste Ziel. Das können die Tumorzentren alleine nicht leisten.

Klinische Studien und der Innovationstransfer zu den Patienten werden ohne die Einbindung der Onkologen in die Regelversorgung aus Krankenhaus und Schwerpunktpraxen nicht möglich sein. Eine sehr viel größere ganzheitliche Anstrengung ist daher nötig.

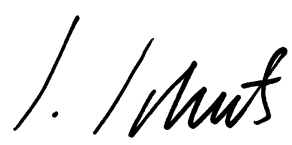

Prof. Dr. Stephan Schmitz

Schriftleiter best practice onkologie

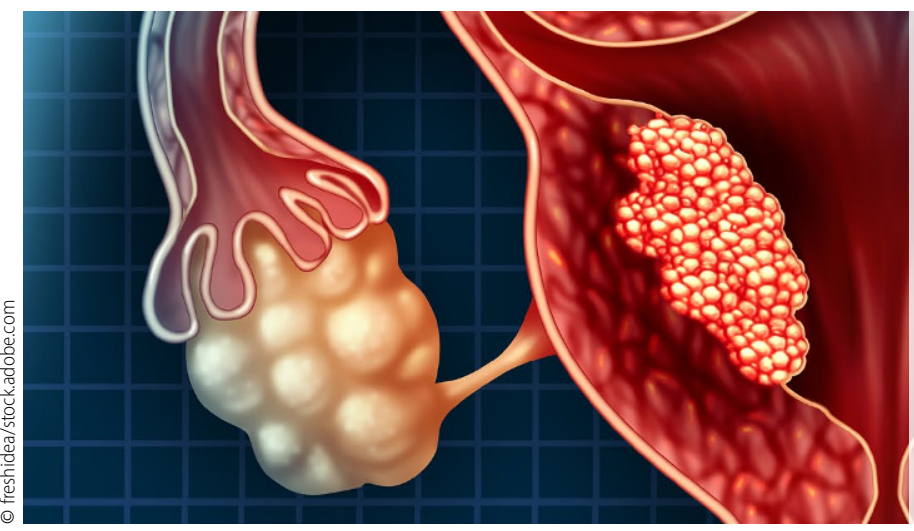

CME-Topic: Update zu uterinen Sarkomen

Uterine Sarkome bilden eine inhomogene Gruppe seltener Tumoren der Uterusmuskulatur. Die Behandlung von betroffenen Patientinnen verlangt sowohl eine hohe pathologische als auch eine hohe gynäkologische Expertise. In diesem Beitrag wird auf das spezifische Management der häufigen Entitäten Leiomyosarkom (LMS) , „low-grade" endometriales Stromasarkom (LG-ESS), "high-grade" endometriales Stromasarkom (HG-ESS) und undifferenziertes Stromasarkom (UES) eingegangen. Lernen Sie neue Therapieoptionen kennen und erfahren Sie mehr über Faktoren, die eine mögliche Prognoseverschlechterung mit sich bringen. 